\title{
Association between skull fractures and types of intracranial hematomas in children with head injury
}

Background and objective: Treating children with head injuries is one of the most

Background and objective: Treating children with head injuries is one of the most frequent causes of admission to the neurosurgical emergency unit in Erbil city. In many cases, the parents ask whether the presence of a skull fracture in their child indicates any association with intracranial hemorrhage. Most of the previous studies focused on the association between skull fractures and intracranial hematomas in the adult population. We conducted this study to determine if there is a statistically significant association between skull fracture and types of intracranial hemorrhage in children.

Methods: A descriptive study was conducted between July 2015 and July 2017 at West Erbil Emergency Hospital. The study sample included children with the head injury whose brain Computerized Tomography (CT)-scan showed intracranial hemorrhage. Data collected using a questionnaire prepared by the researcher. Data were analyzed using descriptive and inferential statistical tests.

Results: A total of 201 children met the inclusion criteria; their ages ranged between 2 months and 17 years. Male to female ratio was $121: 80$. Highest percentages $(64.7 \%)$ of children were $1-5$ years old. The most common $(72.63 \%)$ cause of head injury was fall from height. The most frequent $(48.8 \%)$ intracranial hematoma encountered was an epidural hematoma, followed by intracerebral hematoma and subdural hematomas. There was a highly significant $(P=0.001)$ association between skull fractures and types of intracranial hematomas.

Conclusion: In children, skull fracture increases the incidence of intracranial hematoma. Most common intracranial hematomas in order of frequency were an epidural hematoma, intracerebral hematoma, and subdural hematoma. The most common cause of head injury was fall from height. Most patients were males between one and five years old.

Keywords: Skull fracture; Intracranial hemorrhage; Head injury; Children.

\section{Introduction}

Head trauma is common in the pediatric population and is an important cause of morbidity and mortality in the United States, with an estimated incidence of 250 per 100,000 per year. It accounts for over 7000 deaths, 60,000 hospitalizations, and 600,000 emergency department visits annually among American children. In children, between $10 \%-30 \%$ of head injuries result in the skull fracture, many with associated brain injury. ${ }^{1,2}$ The pathophysiologic event that leads to fracture of the skull bones is well known, but the significance of skull fracture in relation to intracranial hematoma yet to be determined. ${ }^{3}$ When a blunt object strikes the head, the local in-bending causes a compressive strain on the outer table and a tensile strain on the inner table. Because bone is more susceptible to tensile strain, the fracture begins in the inner table; it then propagates along the lines of least resistance. $^{3}$ When the skull strikes a flat object, a linear fracture commonly results. Depressed fractures result from more intense forces delivered over a smaller area of impact. Linear skull fractures are

* Department of Surgery, College of Medicine, Hawler Medical University, Erbil, I raq. 
associated with intracranial injury in $15 \%$ $30 \%$ of patients. Conversely, $40 \%-100 \%$ of intracranial injuries have an associated skull fracture. ${ }^{4}$ Many previous studies on head injuries demonstrated that traumatic intracranial hematoma rarely develops in the absence of skull fractures except in children. Mann et al. in a retrospective analysis performed in relation to different stages of skull development showed that skull fractures became increasingly significant with child's age predicting intracranial hematoma. ${ }^{2}$ Because most of the previous studies focused on the association between skull fractures and intracranial hematomas in the adult population, the researcher thinks it is necessary to perform this research on the pediatric population. This study aimed to find out the association between skull fracture and types of intracranial hematomas in children, the association between children age and cause of trauma, and the association between children age and Glasgow Coma Scale Categories.

\section{Methods}

A descriptive study conducted in the period between July 2015 and July 2017 at the emergency unit of West Erbil Emergency Hospital. Children aged less than eighteen years with head injuries were included in the study. After adequately assessing child's airway, breathing and circulation, rapid neurological examination including the Glasgow Coma Scale (GCS) and pupil reaction to light were performed. Then after ensuring the stability of their condition, the children were sent for a Computerized Tomography (CT-Scan) of the brain, including both brain and bone windows for every child. A questionnaire was developed by the researcher for data collection. The questionnaire included data about the age, gender, cause of head injury, the GCS on admission and presence or absence of skull fracture and/or intracranial hematomas of different types. Before data collection, the verbal agreement was obtained from caregivers to participate in the study. After the results of the brain CT-scan were available; those patients whose CT scan did not show intracranial hematoma of any type were excluded from the study, therefore; only the children whose CT scan showed intracranial hematoma involved in the study. Then this group was divided into two cohorts: those who have the skull fracture and those who have no skull fracture. Twenty-one cases found to have more than one type of intracranial hemorrhage on CT-scan and were excluded from the study. Three children with penetrating brain injuries and intracranial hematomas were also excluded from the study. The statistical package for the social science (version 21) was used for data processing and statistical analysis. Fisher's exact test was used to find the association between the variables. A $P$ value of $\leq 0.05$ was regarded as statistically significant.

\section{Results}

Data were collected during two years; 201 patients who met the criteria were selected as the study sample. Table 1 shows the socio-demographic characteristics of the participants in the study. The highest percentage $(64.7 \%)$ of children were in the 1-5 years age group with a mean and standard deviation of $5.37 \pm 4.44$. Also, the highest percentage $(60.2 \%)$ of children were males. The cause of head injury was fall from height (FFH) in 146 (72.63\%) cases, Road Traffic Accident (RTA) in $43(21.39 \%)$ cases and others like altercation and sport-related injuries in $12(5.98 \%)$ cases, this is shown in Table 2. The most frequent intracranial hematoma encountered was epidural hematoma $(\mathrm{EDH}) 98$ (48.8\%), followed by intracerebral hematoma (ICH) 62 $(30.8 \%)$, subdural hematoma (SDH) 34 $(16.9 \%)$, subarachnoid hemorrhage (SAH) $5(2.49 \%)$ and intraventricular hemorrhage (IVH) 2 (0.99\%). Regarding the fracture type, $124(61.7 \%)$ patients had a linear fracture, $44(21.9 \%)$ patients had depressed fracture, and only $33(16.4 \%)$ 
Association between skull fractures and types of ........

33(16.4 \%) patients had no fracture. Table 3 shows the number and the There was highly significant $(P=0.001) \quad$ percentage of different types of intracranial association between skull fracture and hematomas and its relation to the presence types of intracranial hematomas. or absence of skull fracture.

Table 1: Sociodemographic characteristics of children.

\begin{tabular}{lccc}
\hline Sociodemographic characteristic & & No. & $\%$ \\
\hline Age group (years) & $<1$ & 11 & 5.5 \\
& $1-5$ & 130 & 64.7 \\
& $6-12$ & 35 & 17.4 \\
& $13-17$ & 25 & 12.4 \\
Gender & & $* \overline{\boldsymbol{x}}_{ \pm}$SD & $5.37 \pm 4.44$ \\
& Male & 121 & \\
Total & Female & 80 & 60.2 \\
\hline
\end{tabular}

${ }^{*} \overline{\boldsymbol{x}}=$ mean $\mathrm{SD}=$ standard deviation

Table 2: Causes of trauma among study participants.

\begin{tabular}{lcc}
\hline Cause of trauma & No. & $\%$ \\
\hline Fall From Height (FFH) & 146 & 72.63 \\
Road Traffic Accident (RTA) & 43 & 21.39 \\
${ }^{*}$ Other causes (Altercation and sport-related injuries) & 12 & 5.98 \\
Total & 201 & 100 \\
\hline
\end{tabular}

Table 3: Incidence of types of intracranial hematomas and its association with the skull fracture.

\begin{tabular}{lccccc}
\hline $\begin{array}{l}\text { Types of Intracranial } \\
\text { Hematoma }\end{array}$ & no fracture & $\begin{array}{c}\text { Fracture types } \\
\text { No. (\%) }\end{array}$ & & \\
\hline EDH & $10(30.3)$ & $71(57.3)$ & $17(38.6)$ & $98(100)$ & \\
SDH & $10(30.3)$ & $20(16.1)$ & $4(9.1)$ & $34(100)$ & \\
SAH & $1(3.0)$ & $3(2.4)$ & $1(2.3)$ & $5(100)$ & \multirow{2}{*}{ Depressed } \\
ICH & $10(30.3)$ & $30(24.2)$ & $22(50.0)$ & $62(100)$ & \\
IVH & $2(6.1)$ & $0(0.0)$ & $0(0.0)$ & $2(100)$ & \\
Total & $33(100)$ & $124(100)$ & $44(100)$ & $201(100)$ & \\
\hline${ }^{*}$ Fisher's exact test & & & & \\
\hline
\end{tabular}


There was a statistically highly significant $(P<0.001)$ association between children age and cause of trauma, as the highest percentage of $\mathrm{FFH}$, was from age group 1-5 years old as shown in Table 4. Regarding the severity of head injury based on Glasgow Coma Scale category, there was a statistically highly significant
$(P<0.001)$ association with children's age. As outlined in Table 5, most infants presented with a moderate head injury, the majority of children at 1-5 years old presented with a severe head injury, whereas most children older than six years presented with mild head injury.

Table 4: Association between children age and the cause of trauma.

\begin{tabular}{lccccc}
\hline Age & \multicolumn{5}{c}{ Trauma Cause } \\
FFH & $\begin{array}{c}\text { RTA } \\
\text { No. (\%) }\end{array}$ & $\begin{array}{c}\text { Other } \\
\text { causes } \\
\text { No. }(\%)\end{array}$ & $\begin{array}{c}\text { Total } \\
\text { No. (\%) }\end{array}$ & P value \\
\hline$<1$ & $9(81.8)$ & $2(18.2)$ & $0(0.0)$ & $11(100 \%)$ & \\
$1-5$ & $108(83.1)$ & $17(13.1)$ & $5(3.8)$ & $130(100 \%)$ & $*<0.001$ \\
$6-12$ & $21(60)$ & $10(28.6)$ & $4(11.4)$ & $35(100 \%)$ & \\
$13-17$ & $8(32)$ & $14(56)$ & $3(12)$ & $25(100 \%)$ & \\
\hline
\end{tabular}

*Fisher's exact test

Table 5: Association between children age and severity of head injury based on Glasgow Coma Scale category.

\begin{tabular}{lccccc}
\hline Age & \multicolumn{5}{c}{ The severity of head injury } \\
No. (\%) & $\begin{array}{c}\text { Severe } \\
\text { Head injury }\end{array}$ & $\begin{array}{c}\text { Moderate } \\
\text { Head injury }\end{array}$ & $\begin{array}{c}\text { Mild } \\
\text { Head injury }\end{array}$ & Total & $P$ value \\
\hline$<1$ & $2(18.2)$ & $6(54.5)$ & $3(27.3)$ & $11(100)$ & \\
$1-5$ & $53(40.7)$ & $37(28.5)$ & $40(30.8)$ & $130(100)$ & \\
$6-12$ & $8(22.9)$ & $7(20)$ & $20(57.1)$ & $35(100)$ & \\
$13-17$ & $7(28)$ & $1(4)$ & $17(68)$ & $25(100)$ & \\
\hline
\end{tabular}

*Fisher's exact test 


\section{Discussion}

Treating children with a head injury is one of the most common causes of admission to neurosurgical emergency units in Erbil hospitals. Identifying children having an intracranial hemorrhage is important for early treatment and good outcome. Figure 1 shows different types of skull fractures and the most commonly found intracranial hematomas. The researcher found that the majority of these patients were male; this result had been shown by many other researchers. ${ }^{5-7}$ Also, in the majority of cases, the cause of head injury was fall from a height; this result had been shown by many other researchers who showed that in the pediatric population fall from height is the major cause of head injury. ${ }^{5-10}$ This is another area where future studies to be performed to determine the potential causes of fall from height among children in our community. The researcher found statistically highly significant $(P<0.001)$ association between children age and cause of the trauma as the highest percentage of the children were between the age group 1-5 years old. Also, there was a statistically highly significant $(P<0.001)$ association between children age and GCS, as children 1-5 years have had the highest percentage of low GCS score. The researcher thinks the reason is probably that during this toddler age, children are the most active and least aware of surrounding risks. In this study, the researcher found a statistically highly significant $(P=0.001)$ association between skull fractures and intracranial hematomas.
In this study, about half of the cases were epidural hematomas; approximately one-third of the cases were an intracerebral hematoma, and about onequarter of the cases was the subdural hematoma. This result goes in agreement with the work done by other researchers. Gallagher et al. found that in adults the epidural hemorrhage is far less common than subdural or intracerebral hemorrhage. While in pediatric patients, however, epidural hemorrhage is relatively more common. This is likely because of abundant diploic and dural vascularization normally present in infants and young children, notwithstanding the tight adherence of dura to the inner table of the skull. ${ }^{11-13}$ Subarachnoid hemorrhage and intraventricular hematoma did not show a statistically significant relation with skull fracture ( $P=1.00$ and 0.26 , respectively), probably because of the small number of the cases in the present study. Many other researchers studied the relation between skull fracture and intracranial hematomas in adults, Miller $\mathrm{J}$ et al. in a series of 260 patients with intracranial hematomas; showed that $88 \%$ had skull fracture. ${ }^{14}$ Conversely, Kwan-Hon Chan et al. evaluated 418 head-injured patients for the relation between skull fracture and intracranial hematoma, and found that 405 patients have had no intracranial hematoma on their CT-scan, of this cohort without hematoma, only $13(3.2 \%)$ patients had skull fracture. ${ }^{15}$ In the present study, out of 201 children with intracranial hematomas of all types; 168 (83.58\%) of

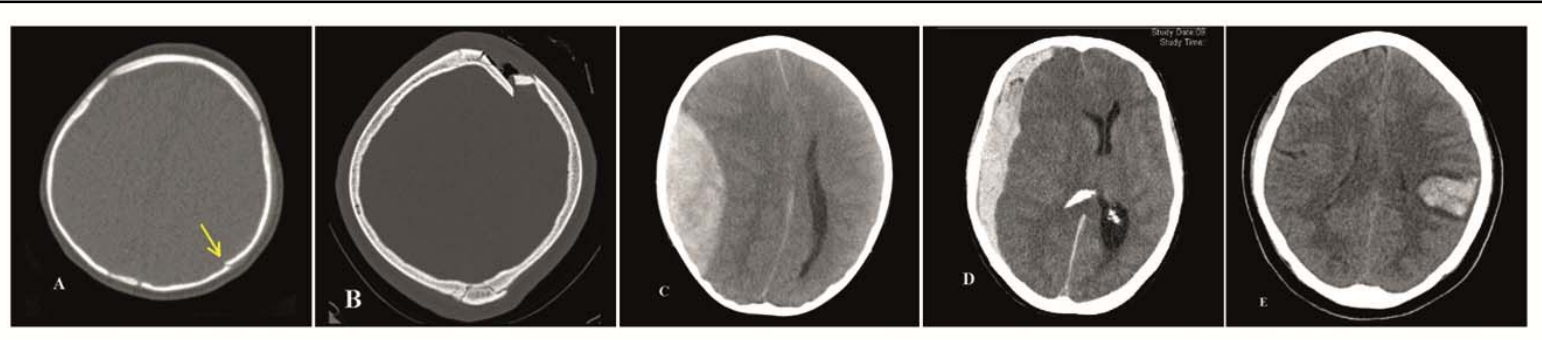

Figure 1: Linear (A) and depressed (B) skull fractures. Three types of most commonly found intracranial hematomas are shown; epidural hematoma $(C)$, subdural hematoma (D) and intracerebral hematoma $(E)$. 
patients had the skull fracture, either linear or depressed. The researcher believes this study is one of the fewest studies focusing on the association between skull fracture and intracranial hematomas in the pediatric population. Future studies are necessary to further determine the association between skull fracture and intracranial hematoma in children because there are many pathophysiologic differences between children and adult head injuries.

\section{Conclusion}

In children, skull fracture increases the incidence of intracranial hematoma. Most common intracranial hematomas in order of frequency are $\mathrm{EDH}, \mathrm{ICH}$, and $\mathrm{SDH}$. The most common cause of head injury is FFH. Most patients were males between one and five years old. We recommend that if a child with head injury found to have the skull fracture on x-ray or CT-scan; it is necessary to transfer the child to a hospital with neurosurgery service.

\section{Competing interests}

The author declares no competing interests.

\section{References}

1. National Center for Injury Prevention and Control. Traumatic brain Injury in the United States: Assessing outcomes in children. Atlanta: Centers for Disease Control and Prevention; 2000.

2. Mann KS, Chan KH, Yue CP. Skull fractures in children: their assessment in relation to developmental skull changes and acute intracranial hematomas. Childs Nerv Syst 1986; 2:258-61.

3. Graham DI, Gennareli TA, McIntosh TK. Trauma. In: Graham DI, Lantos PL, editors. Greenfield's Neuropathology. $7^{\text {th }}$ ed. London: Arnold; 2002. P. 822-98.

4. Arrey EN, Marcia LK, Fletcher S, Cox CS, Sandberg DI. Linear nondisplaced skull fractures in children: who should be observed or admitted? J Neurosurg Pediatr 2015; 16:703-8.

5. Christopher MB, Sanjay N, Oluwaseun A. Pediatric Skull Fracture: the need for surgical intervention, characteristics, complications and outcomes. J Neurosurg Pediatr 2014; 14:205-11.

6. Orman G, Wagner M, Seeberg D, Zamora CA, Oshmyanski A, Tekes A, et al. Pediatric Skull Fracture Diagnosis: Should 3D reconstruction be added as a routine imaging? J Neurosurg Pediatrics 2015; 16:426-31.

7. Dunning J, Daly JP, Lomas JP, Lecky F, Batchelor $J$, Mackway-Jones K. Derivation of the children's head injury algorithm for the prediction of important clinical events decision rule for head injury in children. Arch Dis Child 2006; 91:88591.

8. Schutzman SA, Greenes DS. Pediatric minor head trauma. Ann Emerg Med 2001; 37:65-74.

9. Saadat S, Rashidi N, Rasouli M. Pattern of skull fracture in Iran: Report of the Iran National Trauma Project. Turkish Journal of Trauma and Emergency Surgery 2011; 17(2):149-51.

10. White IK, Pestereva E, Shaikh KA. Transfer of children with isolated linear skull fractures: is it worth the cost? J Neurosurg Pediatr 2016; $17: 602-6$.

11. Gallagher JP, Browder EJ. Extradural hematoma. Experience with 167 patients. J Neurosurg 1968; 29:1-12.

12. Miller JD, Jennet WB. Complications of depressed skull fracture. Lancet 1968; 2:991.

13. Bullock MR, Chesnut R, Ghajar J, Gordon D, Hartl R, Newell WD, et al. Surgical management of acute subdural hematomas. Neurosurgery 2006; 58(3 Suppl):S16-24.

14. Miller J, Piper I, Jones P. Pathophysiology of head injury. In: Narayan RK, Willberger JE, Povlishock JT, eds: Neurotrauma. New York: McGraw-Hill; 1996. P. 61-9.

15. Chan K, Mann K, Yue CP. The significance of skull fracture in acute traumatic intracranial hematomas in adolescents: a prospective study. J Neurosurg 1990; 72:189-94. 